\title{
The effect of strain rate on the compressive deformation behavior of a sintered Ti6Al4V powder compact
}

\author{
A. Taşdemirci ${ }^{\text {a }}$, A. Hızal ${ }^{\text {a }}$, M. Altındiş ${ }^{\text {a }}$ I.W. Hall ${ }^{\text {b }}$, M. Güden ${ }^{\text {a,c }, *}$ \\ ${ }^{a}$ Department of Mechanical Engineering, Izmir Institute of Technology, Gülbahçe Köyü, Urla, Izmir, Turkey \\ ${ }^{\mathrm{b}}$ Department of Mechanical Engineering, University of Delaware, Newark, DE, USA \\ ${ }^{\mathrm{c}}$ Center for Materials Research, Izmir Institute of Technology, Gülbahçe Köyü, Urla, Izmir,Turkey
}

Received 12 February 2007; received in revised form 3 April 2007; accepted 4 May 2007

\begin{abstract}
The high strain rate $\left(220-550 \mathrm{~s}^{-1}\right)$ and quasi-static $\left(0.0016 \mathrm{~s}^{-1}\right)$ compression deformation behavior of a sintered Ti6Al4V powder compact was investigated. The compact was prepared using atomized spherical particles (100-200 $\mu \mathrm{m})$ and contained $38 \pm 1 \%$ porosity. The deformation sequences of the tested samples were further recorded by high speed camera and analyzed as a function of strain. The failure of the compact, which was found to be similar in the studied high strain rate and quasi-static strain rate testing regimes, occurs through particle decohesion along the surface of the two cones in a ductile (dimpled) mode consisting of void initiation and growth and by void coalescence in the interparticle bond region. The effect of strain rate was to increase the flow stress and compressive strength of the compact while the critical strain corresponding to the maximum stress was shown to be strain rate independent.
\end{abstract}

(C) 2007 Elsevier B.V. All rights reserved.

Keywords: Powder processing; Sintering; Ti alloy; Porous Ti alloy; Compression test; Strain rate

\section{Introduction}

There has recently been a great deal of interest centered around the processing [1-11] and use [12-22] of porous Ti components for biomedical applications. This has been primarily driven by the fact that the porous surfaces can facilitate a higher degree of bone in-growth and body fluid transport through threedimensional interconnected arrays of pores, leading to improved implant fixation [23]. The use of porous Ti as the coating layer on the implant surfaces further reduces the extent of stress shielding, which causes well-known implant loosening, and hence prolongs implant life-time.

Porous Ti components can be simply manufactured by means of two different powder sintering methods involving one or two processing steps [2]. In the first method, sintering of powder compacts, the green powder preform compacted at room temperature is directly sintered at a high temperature. In the second

\footnotetext{
* Corresponding author at: Department of Mechanical Engineering, Izmir Institute of Technology, Gülbahçe Köyü, Urla, Izmir, Turkey. Tel.: +90 232498 6595; fax: +90 2324986505 .

E-mail address: mustafaguden@iyte.edu.tr (M. Güden).
}

method also known as the space holder method, a solid space holding material such as ammonium hydrogen carbonate, and carbamide particles is mixed with Ti powder and the mixture is pre-shaped under pressure. The space holder is then removed in an intermediate heating stage at a relatively low temperature, and finally the preform is sintered at a temperature of $1100-1400{ }^{\circ} \mathrm{C}$ [2]. The size, level and geometry of pores of the final sintered part can be easily altered by varying the size, amount and shape of the space holder.

Although, both methods allow a direct near net-shape fabrication route for porous implant components, the porosity levels, pore sizes and shapes of the components produced are quite different from each other. In the space holder method, the resulting porous structure resembles the structure of the open-cell foamedmetal with relatively high porosity levels ranging between 35 and $80 \%$ and large pore sizes ranging between 200 and $500 \mu \mathrm{m}$, depending on the volume, size and shape of the space holder used [24]. On the other hand, in the powder compact sintering method, the porosity level is relatively low, varying between 5 and $38 \%$, the average pore size is relatively small. Moreover, porosity and pore size vary with the powder size, applied cold compaction pressure and sintering temperature $[7,25]$. Since lower porosity levels and smaller pore sizes are attained as com- 


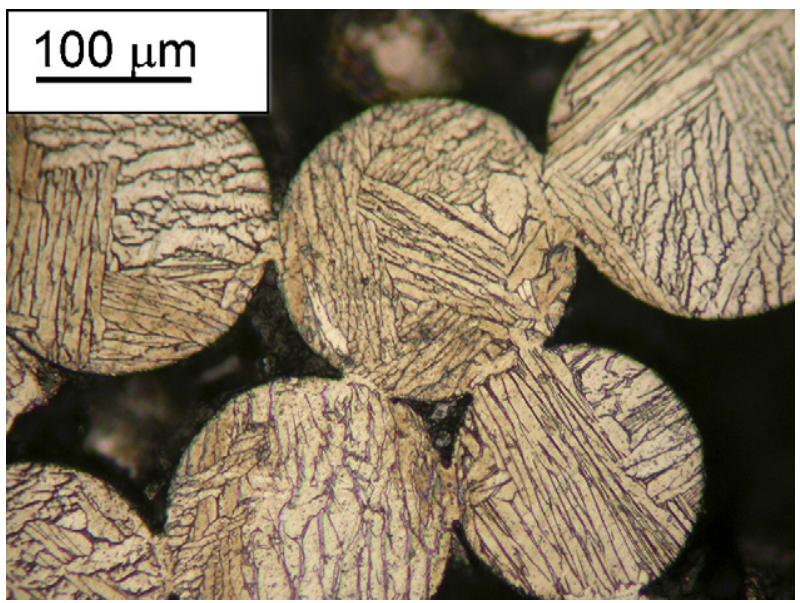

Fig. 1. Optical micrograph of the sintered powder compact showing Widmanstätten microstructure.

pared with Ti foam produced by space holder method, sintered powder compacts exhibit higher strength and modulus values. It was previously reported that the compressive yield strength of sintered Ti compacts was lower than that of the human cortical bone, a result which was proposed to be due to the relatively low yield strength of Ti powder used [7]. The use of stronger Ti6Al4V (Ti64) alloy powder in the sintered powder compacts, however, increased the yield strength to values comparable to that of human cortical bone [25].

In bone-replacement, mechanical strength retention of the implant at increasing loading rates should also be considered. An extensive literature survey by Yeni and Fyrie [26] has remarked on the strain rate dependent mechanical properties of natural bone. A recent study on the high strain rate testing of trabecular and cortical bone using a Split Hopkinson Pressure Bar (SHPB) apparatus has further shown that the ultimate strength values increased while the modulus values decreased with increasing strain rate [27]. In the present experimental study, the compressive mechanical behavior of a Ti64 powder compact that can potentially be used in biomedical applications as load carrying implants including human cortical bone replacement, in ballistic applications such as protection against projectiles and in crash absorption applications was investigated at high strain rates using a compression SHPB apparatus. In a previous study, the high strain rate and quasi-static strain rate compression behavior of a similar Ti64 powder compact with a lower aspect ratio $(l / d=0.66)$ and a porosity level $(37 \pm 1 \%)$ was determined [25], while in this study longer cylindrical compact specimens were tested. In addition, the accompanying deformation sequences of the powder compacts at high strain rates as a function of strain were determined using a high-speed camera. The compression behavior and deformation mechanisms of the compacts at high strain rates were further compared with those of quasi-static strain rate.

\section{Materials and testing methods}

The sintered Ti64 alloy powder compacts were prepared using atomized spherical particles (Phelly Materials Inc.). The chemical composition of the powder [25] complied with ASTM 1580-1 standard [28]. The particle sizes ranged between 100 and $200 \mu \mathrm{m}$ with a mean particle size of $170 \mu \mathrm{m}$. Green powder compacts, $26.5 \mathrm{~mm}$ in length and $16.5 \mathrm{~mm}$ in diameter were compacted at room temperature inside a tool steel die at a pressure of $400 \mathrm{MPa}$ using a polyvinyl alcohol solution (10\% by volume) as the binding material in an amount of $5 \%$ by weight. The sintering of green compacts was performed in a tightly enclosed horizontal tube furnace under a high purity $(99.998 \%)$ Ar flux $\left(400 \mathrm{~cm}^{3} / \mathrm{min}\right)$ at $1200^{\circ} \mathrm{C}$ for $2 \mathrm{~h}$. The compacts were inserted into the furnace at room temperature inside an enclosed Ti box on a graphite plate which prevented the bonding between Ti box and compacts. The compacts were heated and cooled at a rate of $5^{\circ} \mathrm{C} / \mathrm{min}$. During the heating cycle under Ar flux, the compacts were kept at $450{ }^{\circ} \mathrm{C}$ for $1 / 2 \mathrm{~h}$ in order to allow complete burning-off of the binder. The compacts showed 1.3 and $2.7 \%$ sintering shrinkages in length and diameter, respectively. The specimen dimensions, $\sim 16 \mathrm{~mm}$ in diameter and $\sim 26 \mathrm{~mm}$ in height $(l / d \sim 1.6)$, were the same for both quasi-static and high strain rate tests. The ends surfaces of the compacts were ground and then polished before testing. The porosity level of the compacts was measured to be $38 \pm 1 \%$. Compacts with similar powder sizes and porosity levels were previously determined to contain almost $100 \%$ three-dimensional interconnected pores with a mean pore size of $63 \mu \mathrm{m}$ [25]. The microstructure of the powder was composed of needle-like $\alpha$-phase, referred as acicular alpha $(\alpha)$ and sintering at high temperature above the beta $(\beta)$-transition temperature $\left(1050{ }^{\circ} \mathrm{C}\right)$ and subsequent slow rate cooling in the furnace under $\mathrm{Ar}$ atmosphere resulted in the development of the so-called Widmanstätten microstructure (Fig. 1). Detailed information on the as-received powder microstructure and microstructure development after sintering is given elsewhere [25].

High strain rate compression tests were performed using a compression type Split Hopkinson Pressure Bar (SHPB) set-up. A cylindrical specimen is sandwiched between the incident and transmitter bars, Fig. 2, and a constant amplitude elastic wave is generated by the striker bar. Strain gages mounted on the incident and transmitter bars allow the compressive stress-strain

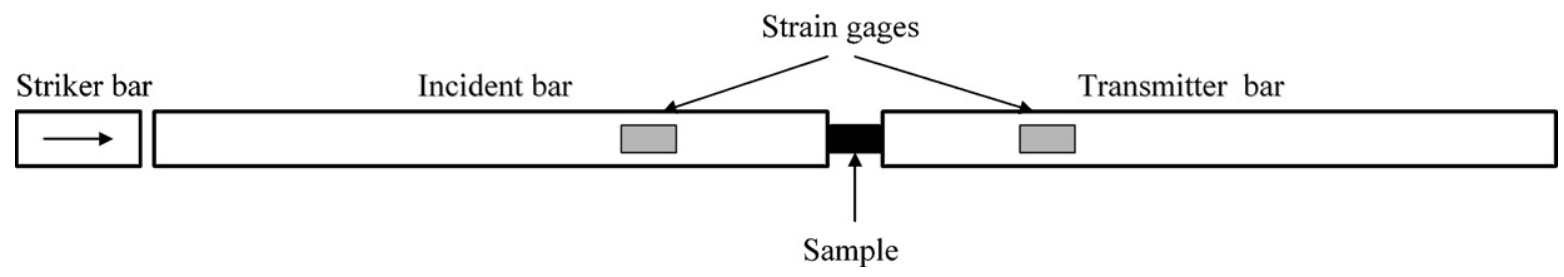

Fig. 2. Schematic diagram of compression SHPB set-up. 
response of the specimen to be established using uniaxial elastic wave theory. A more detailed overview of SHPB testing is found in Ref. [29]. The SHPB apparatus used consists of Inconel 718 bars: the lengths of striker, incident and transmitter are 362 , 3450 and $1850 \mathrm{~mm}$, respectively, all with a diameter of $19 \mathrm{~mm}$. Detailed information about the SHPB used is given in elsewhere [30]. The strain rate $(\dot{\varepsilon})$, the strain $(\varepsilon)$ and the stress $(\sigma)$ of the tested sample were calculated using the following equations:

$\dot{\varepsilon}(t)=-\frac{2 C_{\mathrm{b}}}{L_{\mathrm{S}}} \varepsilon_{\mathrm{r}}(t)$,

$\varepsilon(t)=-\frac{2 C_{\mathrm{b}}}{L_{\mathrm{s}}} \int_{0}^{t} \varepsilon_{\mathrm{r}}(t)$,

$\sigma(t)=\frac{E_{\mathrm{b}} A_{\mathrm{b}}}{A_{\mathrm{s}}} \varepsilon_{\mathrm{t}}(t)$,

where $C_{\mathrm{b}}$ is the elastic wave velocity in the bar, $E_{\mathrm{b}}$ the elastic modulus of the bar, $L_{\mathrm{s}}$ the sample length and $A_{\mathrm{s}}$ and $A_{\mathrm{b}}$ are the sample and bar cross-sectional areas, respectively. $\varepsilon_{\mathrm{r}}$ and $\varepsilon_{\mathrm{t}}$ are reflected and transmitted strains measured from strain gages on the bar, respectively. Eqs. (1)-(3) are only valid when the force equilibrium in the specimen is established and the force equilibrium in the specimen is further checked using a dimensionless number $(R)[31]$ :

$R=-\frac{2\left(F_{1}-F_{2}\right)}{\left(F_{1}+F_{2}\right)}$,

where $F_{1}$ and $F_{2}$ are the front and back surface forces, respectively, on the SHPB test sample. This number is a measure of the extent of deviation from stress equilibrium in the specimen. When the value of $R$ reaches 0 , stress equilibrium in the sample is reached. Since the transmitter bar of the used SHPB is shorter than the incident bar, the tensile wave reflected from the transmitter bar end separates the bars and, therefore, the sample deforms only once under compression. The samples in SHPB were deformed at average strain rates of nearly 220, 340 and $550 \mathrm{~s}^{-1}$ and at least two tests were performed for each strain rate. The deformation process at high strain rates was observed by photographing the specimen sequentially in predetermined short time intervals (of the order of few microseconds) using a high speed camera during SHPB testing. With the Ultra 8 high-speed camera used for the present study, a maximum of 8 frames can be photographed at speeds up to 100 million frames per second. In the time domain, the interframe time can be varied between $10 \mathrm{~ns}$ and $1 \mathrm{~ms}$. The camera can be synchronized with the incident bar strain-gage or can be delayed to photograph the events of interest only.

Quasi-static compression tests were conducted on a displacement controlled SHIMADZU AG-I universal tensioncompression test machine with cross-head speeds of $2.5 \mathrm{~mm}$ per min, corresponding to strain rates of $0.0016 \mathrm{~s}^{-1}$. In quasistatic strain rate testing, the strain values were corrected by subtracting the test machine displacement calculated from measured machine compliance from the total displacement. Four compression tests were performed at the quasi-static strain rate studied.

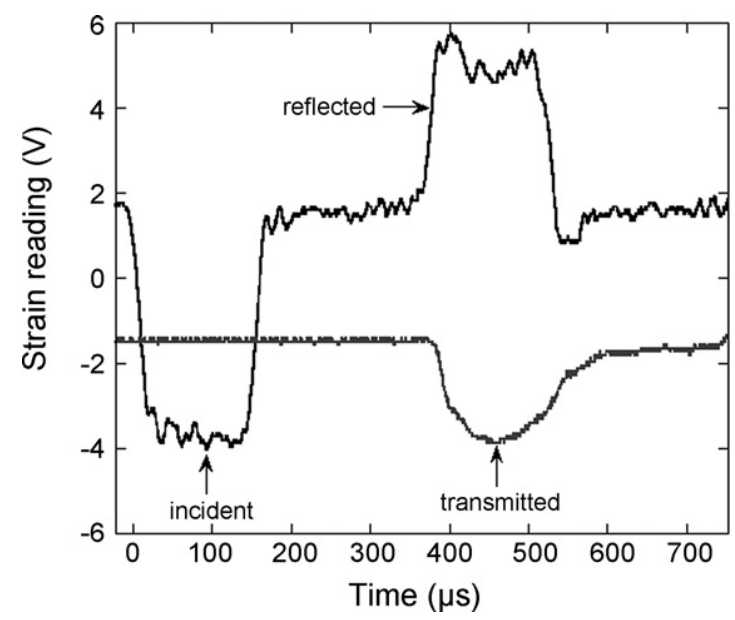

Fig. 3. Typical SHPB strain gage readings of Ti64 compact.

\section{Results and discussions}

Typical SHPB incident, reflected and transmitted strain readings for a tested compact sample are shown in Fig. 3 as a function of time. The corresponding stress and strain rate versus strain curves are further shown in Fig. 4. As is also noted in Fig. 4, the strain rate in a typical SHPB testing is not constant. The strain rate for the compact is generally high at the beginning of the deformation, decreases gradually as the strain increases and increases near the end of the deformation. Therefore, an average strain rate is calculated for each test by integrating the strain rate values until about a final strain (point a in Fig. 4) and dividing the integration by the final strain. The dotted line in Fig. 4 shows the calculated average strain rate. Fig. 5 shows the variation of the dimensionless number $R$ in Eq. (4) with the strain in a compact sample tested at the highest average strain rate studied, $557 \mathrm{~s}^{-1}$. It is seen that the equilibrium condition in the sample, i.e. $R$ approaches 0 , attained at strain values above 0.013 ; therefore, the stress values above this critical strain level are considered to be valid.

Typical compression stress-strain curve of the compact at high strain rate $\left(227,339\right.$ and $\left.557 \mathrm{~s}^{-1}\right)$ and quasi-static strain rate $\left(0.0016 \mathrm{~s}^{-1}\right)$ are shown in Fig. 6. Stress-strain curves of three

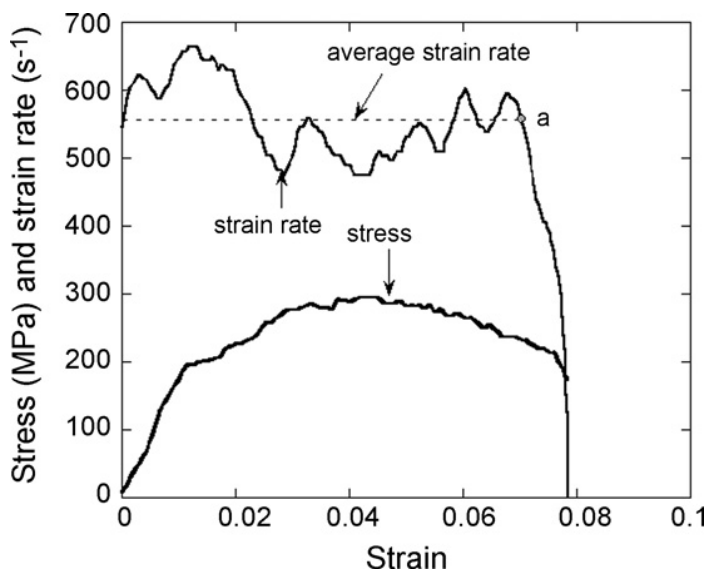

Fig. 4. Stress and strain rate vs. strain graphs of the strain recordings in Fig. 3. 


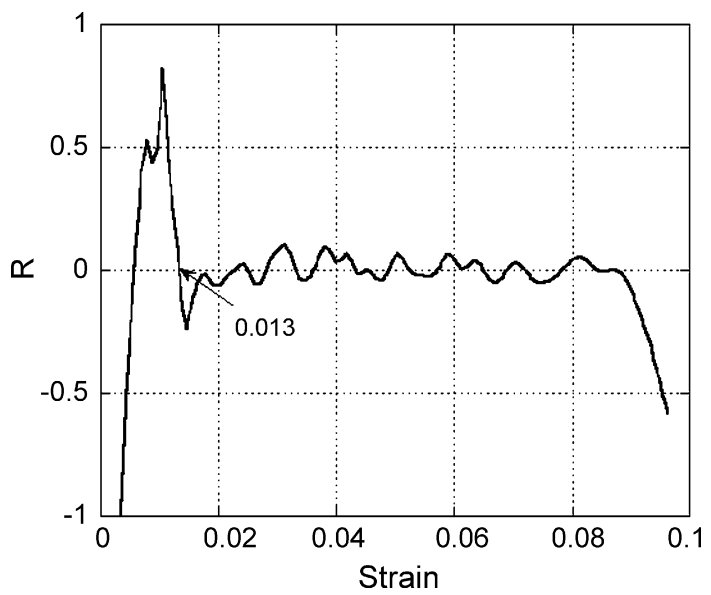

Fig. 5. Dimensionless number $R v s$. strain for the compact sample tested at an average strain rate of $557 \mathrm{~s}^{-1}$.

samples are shown in the same figure for the quasi-static strain rate testing in order to show the variation of the stress values between each samples tested at the same strain rate. The effect of strain rate is clearly seen; it increases the flow stresses and compressive strengths (the maximum stress) of the compact. The deformation of the compact for both strain rate regimes can be divided in four different regions as numbered in Fig. 6 from I to IV. The photographs of the deformed compact samples for high $\left(557 \mathrm{~s}^{-1}\right)$ and quasi-static strain rate $\left(0.0016 \mathrm{~s}^{-1}\right)$ at strain lev-

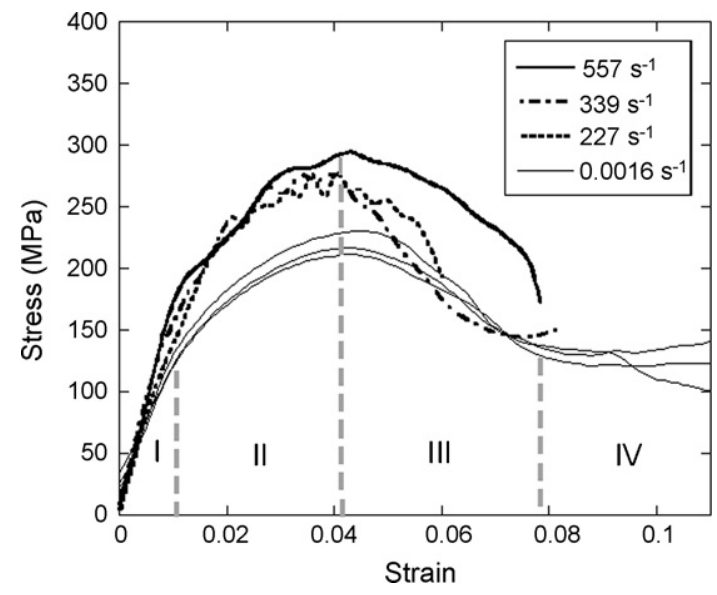

Fig. 6. Typical compression stress-strain curves of the compact at high and quasi-static strain rates with four different deformation regions.

els corresponding to each deformation region are further shown in Figs. 7 and 8, respectively. The deformation mechanisms of the compact are interpreted based on the stress-strain curves in Fig. 6 and the corresponding photographs of the deformed compacts shown in Figs. 7 and 8.

The compact is elastically compressed until about $1 \%$ strain at both strain rates, reflected in the linear portion of the stress-strain curves in region I. In this region, it is presumed that the sintered particles are compressed uniformly at quasi-static strain

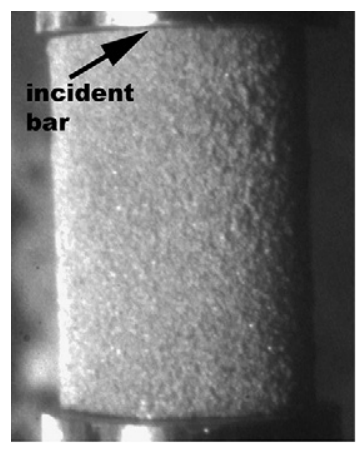

(a)

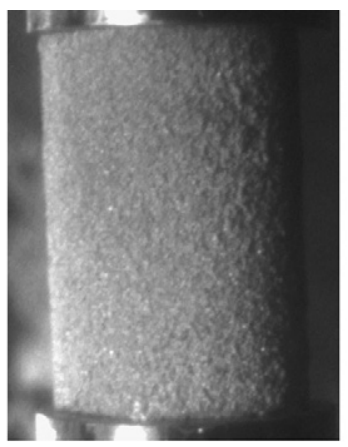

(b)

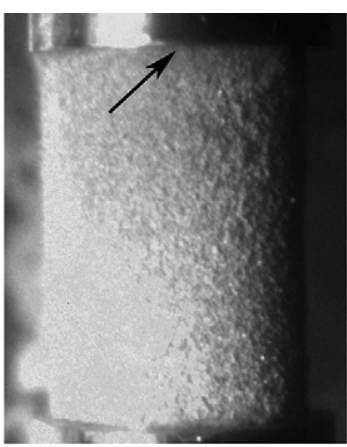

(c)

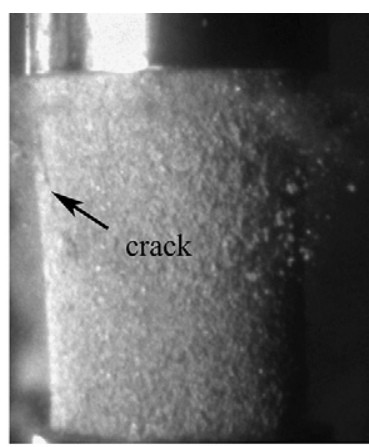

(d)

Fig. 7. High speed camera recordings of a compact sample tested at $227 \mathrm{~s}^{-1}$ to various strains: (a) $0 \%$, (b) $2.5 \%$, (c) $4.6 \%$ and (d) $8 \%$.

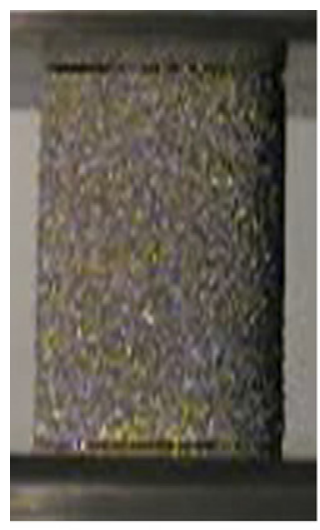

(a)



(b)

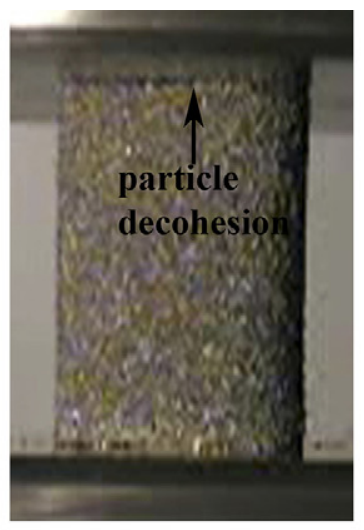

(c)

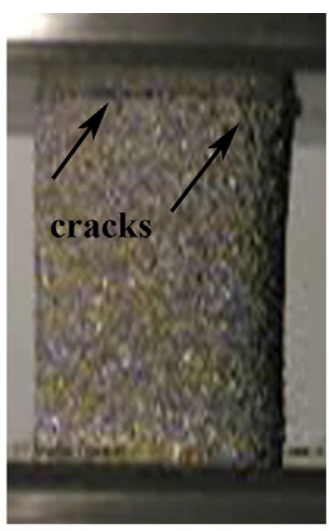

(d)

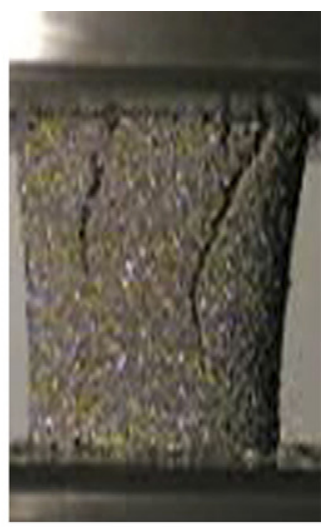

(e)

Fig. 8. Pictures of a quasi-statically tested compact sample at strains of (a) $0 \%$, (b) $2 \%$, (c) $4 \%$, (d) $5 \%$ and (e) $10 \%$. 
rate, while the stress distribution in the samples tested at high strain rate is non-uniform. The elastic deformation continues until about $1 \%$ strain, nearly corresponding to the proportional limit or yield strength of the compact. Inelastic deformation of the particles presumably takes place in region II and continues until about the compressive strength. Figs. 7 and $8(\mathrm{~b})$ show pictures of the deformed compacts at strains of 2.5 and 2 in region II for dynamically and quasi-statically tested samples, respectively. No particle decohesion is noted from the surfaces of the compact samples in region II. Particle decohesion starts to occur at one of the ends of the compact sample at about $4 \%$ strains in dynamically tested compact sample (Fig. 7(c)), while it is clearly observed from the video recordings of the quasi-statically tested sample that particle decohesion starts from the surface of the sample at a strain of $\sim 4 \%$ (Fig. 8(c)), nearly corresponding to the maximum stress in Fig. 6.

In region III, the deformation starts to become non-uniform as the localized deformation builds up on the surfaces of two cones, whose apices meet at the center of the specimen. Particle decohesion starts from one of the ends of the sample and proceeds along the surfaces of the cone. The vertical surface cracks in this region become visible, again starting from one end of the sample (Figs. 7 and 8(d)) and the stress values decrease accordingly in this region. Following particle separation along the diagonal axis at strains of about $8 \%$, the two cone apices shear on top of each other (arrow in Fig. 9); hence, stress values fluctuate around a constant stress in region IV. Pictures of an untested sample and dynamically and quasi-statically tested and failed samples are shown in Fig. 9. It is noted in Fig. 9 that the failure modes of the compact are very similar for dynamically and quasi-statically tested samples, except that the quasi-statically tested sample deformed until larger strains.
SEM micrographs of the fracture (separated) surfaces of the failed compact specimens and interparticle bond regions shown in Figs. 10 and 11(a) and (b) for dynamically and quasistatically tested samples, respectively. These micrographs show some of the features of the important deformation mechanisms of the compacts including (i) the separation of particles primarily occurs at the interparticle bond region (Figs. 10 and 11(a)) and (ii) the fracture of interparticle bond region is mainly ductile type composing of dimples (Figs. 10 and 11(b)). The interparticle bond regions are, however, largely smeared in the sample tested at high strain rate (shown by arrows in Fig. 10(a)). Void formation at the interparticle bond region primarily in $\alpha$ platelets is observed (Fig. 12). The growth and coalescence of these voids eventually lead to development of macrocracks and complete separation of interparticle bond region. Void initiation and growth and void coalescence leading to ductile dimple type of failure were commonly observed in bulk Ti64 alloys tested under shear and compression at quasi-static and dynamic strain rates [32-36].

The proportional limit of the compact at the quasi-static strain rate was found to be $104 \mathrm{MPa}(98-108 \mathrm{MPa})$. The stress values corresponding to $2 \%$ strain vary between 171 and $183 \mathrm{MPa}$ for quasi-static testing and 225-250 MPa for high strain rate testing between $\sim 220$ and $550 \mathrm{~s}^{-1}$. The maximum stress varies between 210 and $228 \mathrm{MPa}$ at the quasi-static strain rate, while it increases to values of 265-291 MPa in the high strain rate regime studied. The values of compressive strength of the compact are, however, slightly lower than those of smaller aspect ratio compact samples (0.66) tested at similar strain rates [25]. The discrepancy arises partly from slightly lower porosities of the compacts samples tested and partly from the higher specimen aspect ratio. The critical strain, the strain corresponding to the maximum stress, started to develop in compacts of lower aspect ratio in the range



Fig. 9. Photographs of the untested, dynamically tested $\left(227 \mathrm{~s}^{-1}\right)$, and quasi-statically tested compact samples. 
(a)

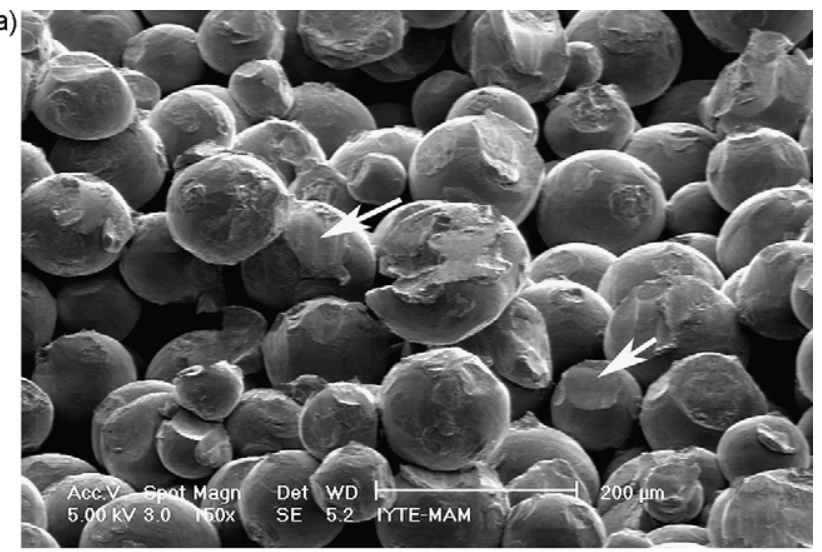

(b)

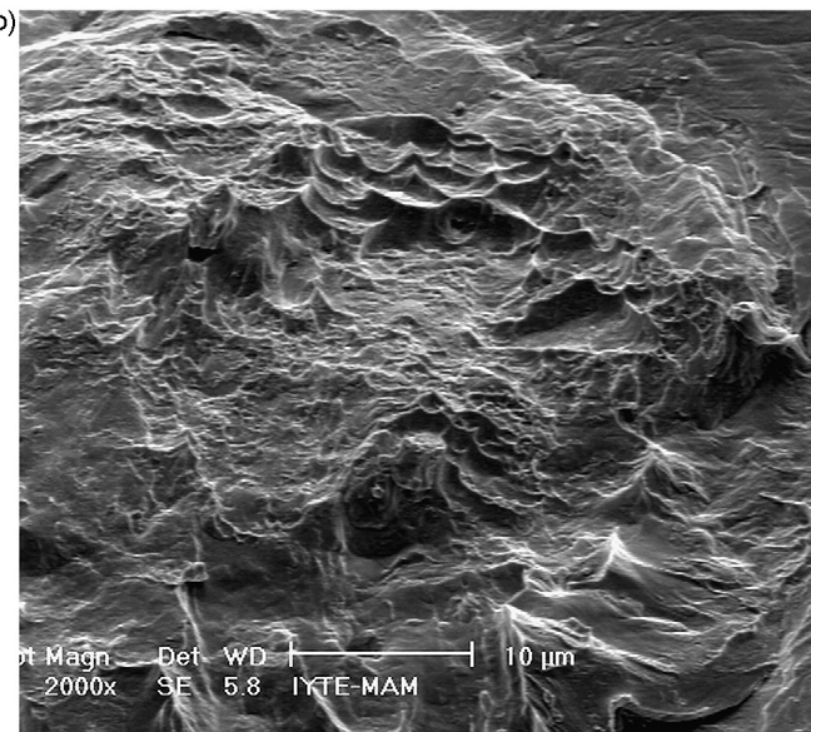

Fig. 10. SEM images of a dynamically tested and failed compact sample: (a) image from the section "a" in Fig. 9 and (b) dimpled mode of failure of interparticle bond region.

between 7 and 8\% [25]; in contrast, higher aspect ratio compact samples with slightly higher porosity tested in this study show lower critical strains, $4 \%$. This is attributed to higher aspect ratio of the compact tested, resulting in the development of the localized deformation at earlier strains. It is further noted the critical strain for localization is strain rate independent within the studied strain rate regime. This is in good agreement with previous studies on a bulk Ti64 alloy [32]. The critical strain level was, however, shown to be quite different in the Widmanstätten and equiaxed microstructures of a bulk Ti64 alloy; although Widmanstätten microstructure showed strain localization at 8-10\% strains, equiaxed structure did not show any localized shearing [32], confirming a strong dependency of mechanical properties on the microstructure. Generally, as the strain rate increased, both yield and flow stress values of bulk Ti64 alloy were found to increase [32-36]. The similar strain rate dependency of powder compacts with bulk alloys found previously in Ti64 and iron alloys $[32,37]$ tends to lead to the conclusion that strain rate dependency of the powder compact is simply derived from the rate dependency of bulk Ti64 alloy. The yield strength of compact was also found to be comparable to that of human cor- (a)

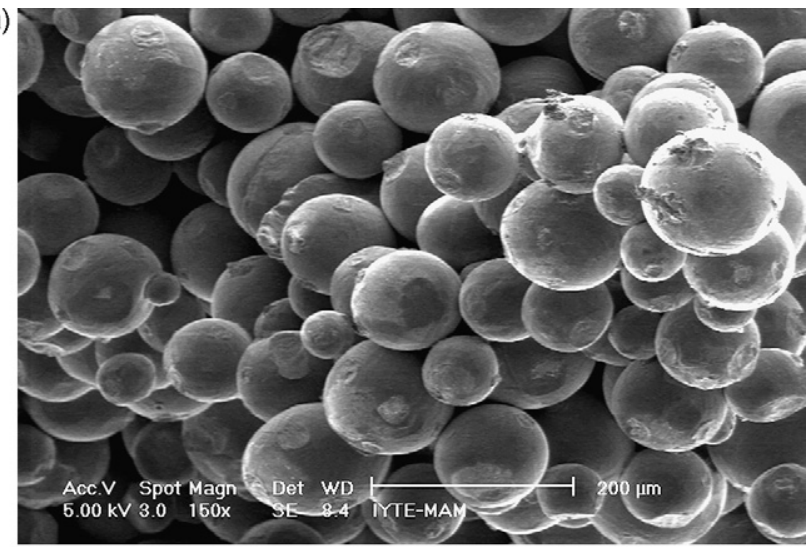

(b)

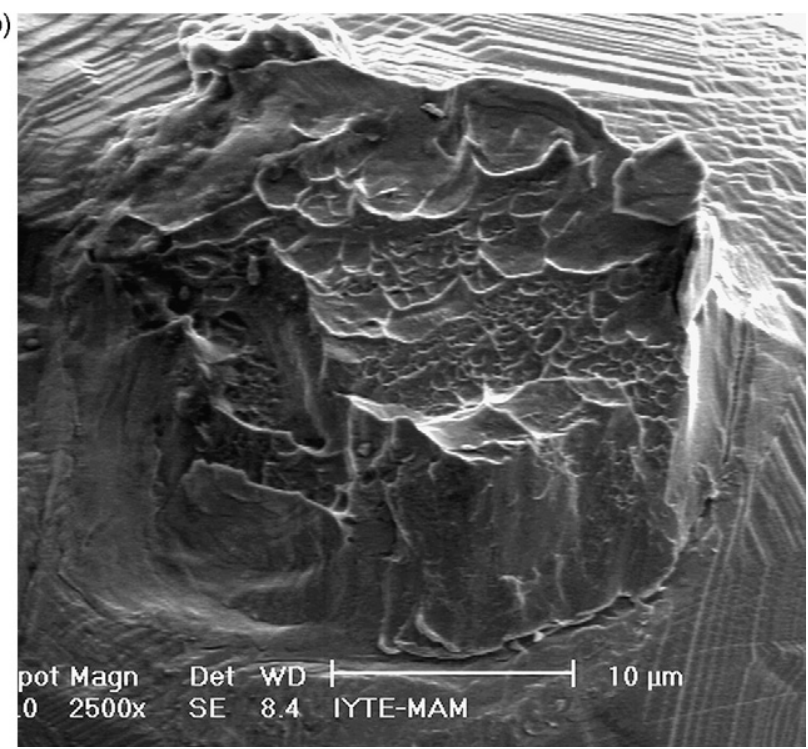

Fig. 11. SEM images of a quasi-statically tested and failed compact sample: (a) image from the section b in Fig. 9 and (b) dimpled mode of failure of interparticle bond region.

tical bone, 104-125 MPa measured within the strain rate regime of $2-5 \times 10^{-2} \mathrm{~s}^{-1}$ [38]; hence, this material also satisfies the strength requirement of cortical bone replacement. The proof stresses of the Ti powder compacts in the porosity range of $30-35 \%$ were previously shown to be less than $100 \mathrm{MPa}$ [7]. The

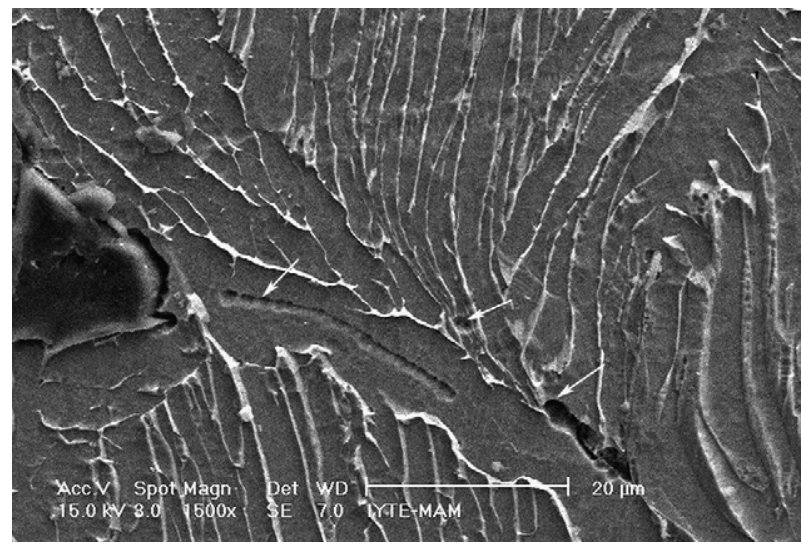

Fig. 12. The interparticle bond region of a quasi-statically tested compact sample, showing voiding and void coalescence. 
higher proportional limit of the studies powder compacts than Ti compacts shows the potential for using Ti64 alloy powders in increasing of yield strength of sintered powder compacts.

\section{Conclusions}

High strain rate and quasi-static compression behavior of a sintered Ti64 alloy compact with a porosity level of $38 \%$ was determined. The deformation sequences of the dynamically tested compact samples were recorded in the SHPB during testing using a high speed camera. It was found that the strain rate increased both flow stress values and compressive strength of the compact within the studied strain rate regime. The failure of the compact was found to be due to particle decohesion on the surfaces of cones starting to form at each end of the specimen, and was the same for dynamically and quasi-statically tested samples. The critical strain corresponding to the initiation of particle decohesion was, however, strain rate independent. The microscopic analyses of deformed samples of compact have further shown that fracture occurred in a ductile (dimpled) mode consisting of void initiation and growth and by void coalescence in the interparticle bond region.

\section{Acknowledgement}

The authors would like to thank the Technology Development Foundation of Turkey (TTGV) for the grant \#TTGV-102/T13.

\section{References}

[1] M. Bram, A. Laptev, H.P. Buchkremer, D. Stover, Materialwissenschaft Und Werkstofftechnik 35 (2004) 213-218.

[2] D.C. Dunand, Adv. Eng. Mater. 6 (2004) 369-376.

[3] Z. Esen, S. Bor, Scr. Mater. 56 (2007) 341-344.

[4] M. Guden, E. Celik, S. Cetiner, A. Aydin, Biomaterials: from Molecules to Engineered Tissues, vol. 553, Kluwer Academic/Plenum Publications, New York, 2004, pp. 257-266.

[5] A. Laptev, M. Bram, H.P. Buchkremer, D. Stover, Powder Metall. 47 (2004) 85-92.

[6] H. Li, Q.F. Yu, B. Zhang, H. Wang, H.S. Fan, X.D. Zhang, Rare Metal Mater. Eng. 35 (2006) 154-157.

[7] I.H. Oh, N. Nomura, N. Masahashi, S. Hanada, Scr. Mater. 49 (2003) $1197-1202$.

[8] R. Ricceri, F. Arcuri, P. Matteazzi, Journal De Physique Iv 11 (2001) 51-57.

[9] E.D. Spoerke, N.G. Murray, H.L. Li, L.C. Brinson, D.C. Dunand, S.I. Stupp, Acta Biomater. 1 (2005) 523-533.
[10] C.E. Wen, Y. Yamada, K. Shimojima, Y. Chino, H. Hosokawa, M. Mabuchi, J. Mater. Res. 17 (2002) 2633-2639.

[11] Y.O.Y. Higuchi, H. Nakajima, Adv. Eng. Mater. 8 (2006) 907-912.

[12] T.Y. El Sayegh, R.M. Pilliar, C.A.G. McCulloch, J. Biomed. Mater. Res. 61 (2002) 482-492.

[13] N.G.M. Erik, D. Spoerke, Huanlong Li, L.C. Brinson, D.C. Dunand, S.I. Stupp, Acta Biomaterialia 1 (2005).

[14] K.H. Frosch, I. Sondergeld, K. Dresing, T. Rudy, C.H. Lohmann, J. Rabba, D. Schild, J. Breme, K.M. Stuermer, J. Orthop. Res. 21 (2003) 213-223.

[15] S. Fujibayashi, M. Neo, H.M. Kim, T. Kokubo, T. Nakamura, Biomaterials 25 (2004) 443-450.

[16] M.A. Lopez-Heredia, E. Goyenvalle, E. Aguado, C. Leroux, M. Dorget, P. Layrolle, Bioceramics 18, Pts 1 and 2, vol. 309-311, 2006, pp. 1099-1102.

[17] M.L. Melikyan, V.I. Itin, Tech. Phys. Lett. 28 (2002) 673-674.

[18] B. Otsuki, M. Takemoto, S. Fujibayashi, M. Neo, T. Kokubo, T. Nakamura, Biomaterials 27 (2006) 5892-5900.

[19] J.P. St-Pierre, M. Gauthier, L.P. Lefebvre, M. Tabrizian, Biomaterials 26 (2005) 7319-7328.

[20] A. Tache, L. Gan, D. Deporter, R.M. Pillar, Int. J. Oral Maxillofac. Implants 19 (2004) 19-29.

[21] M. Takemoto, S. Fujibayashi, M. Neo, J. Suzuki, T. Matsushita, T. Kokubo, T. Nakamura, Biomaterials 27 (2006) 2682-2691.

[22] Y. Wu, H. Li, C.L. Deng, B.C. Yang, X.D. Zhang, J. Inorg. Mater. 20 (2005) $112-118$.

[23] M. Long, H.J. Rack, Biomaterials 19 (1998) 1621-1639.

[24] C.E. Wen, Y. Yamada, K. Shimojima, Y. Chino, T. Asahina, M. Mabuchi, J. Mater. Sci.-Mater. Med. 13 (2002) 397-401.

[25] M. Guden, E. Celik, E. Akar, S. Cetiner, Mater. Characterization 54 (2005) 399-408.

[26] Y.N. Yeni, D.P. Fyhrie, J. Biomech. 36 (2003) 1343-1353.

[27] F. Ferreira, M.A. Vaz, J.A. Simoes, Mater. Characterization 57 (2006) 71-79.

[28] A.F. 1580-95, Standard specification for titanium and Ti6Al4V alloy powders for coating surgical implants.

[29] G.T. GRAY III, Methods in Materials Research, Wiley, New York, NY, 1997.

[30] M. Guden, I.W. Hall, Mater. Sci. Eng. A-Struct. Mater. Prop. Microstruct. Process. 232 (1997) 1-10

[31] G. Ravichandran, G. Subhash, J. Am. Ceram. Soc. 77 (1994) 263-267.

[32] M.G. daSilva, K.T. Ramesh, Mater. Sci. Eng. A-Struct. Mater. Prop. Microstruct. Process. 232 (1997) 11-22.

[33] A.J.W. Johnson, C.W. Bull, K.S. Kumar, C.L. Briant, Metall. Mater. Trans. A-Phys. Metall. Mater. Sci. 34 (2003) 295-306.

[34] D.G. Lee, S. Kim, S. Lee, C.S. Lee, Metall. Mater. Trans. A-Phys. Metall. Mater. Sci. 32 (2001) 315-324.

[35] D.G. Lee, Y.H. Lee, S. Lee, C.S. Lee, S.M. Hur, Metall. Mater. Trans. A-Phys. Metall. Mater. Sci. 35A (2004) 3103-3112.

[36] S. Nemat-Nasser, W.G. Guo, V.F. Nesterenko, S.S. Indrakanti, Y.B. Gu, Mech. Mater. 33 (2001) 425-439.

[37] M.G. daSilva, K.T. Ramesh, Int. J. Plasticity 13 (1997) 587-610.

[38] A. Burstein, D. Reilly, M. Martens, J. Bone Joint Surg. 58A (1976) 82-86. 